\title{
Application of biosphere models in the BIOMOSA project: A comparative assessment of five European radioactive waste disposal sites
}

\author{
R. Kowe ${ }^{1}$, S. Mobbs ${ }^{1}$, G. Proehl ${ }^{2}$, U. Bergstrom ${ }^{3}$, B. Kanyar ${ }^{4}$, G. Olyslaegers ${ }^{5}$, \\ T. Zeevaert ${ }^{5}$ and I. Simon ${ }^{6}$ \\ ${ }^{1}$ National Radiological Protection Board, Chilton, UK \\ ${ }^{2}$ GSF-Institute for Radiation Protection, Neuherberg, Germany \\ ${ }^{3}$ Studsvik Eco \& Safety, Nyköping, Sweden \\ ${ }^{4}$ University of Veszprem, Hungary \\ ${ }^{5} \mathrm{SCK} \cdot \mathrm{CEN}, \mathrm{Mol}$, Belgium \\ ${ }^{6}$ CIEMAT, Madrid, Spain
}

\begin{abstract}
The BioMoSA (Biosphere Models for Safety Assessment of Radioactive Waste Disposal) project was part of the EC fifth framework research program. The main goal of this project was the improvement of the scientific basis for the application of biosphere models in the framework of long-term safety studies of radioactive waste disposal facilities. Another aim of the project was to provide operators and regulatory bodies with guidelines for performance assessments of repository systems. The study focused on the development and application of site-specific models and a generic biosphere tool BIOGEM (BIOsphere GEneric Model), using the experience from National programs and the IAEA BIOMASS reference biosphere methodology. The models were applied to 5 typical locations in Europe, resulting in estimates of the annual individual doses to the critical groups and the ranking of the importance of the pathways for each of the sites. The results of the site-specific and generic models were then compared. Uncertainty in the results was estimated by means of stochastic calculations which allowed a comparison of the overall model uncertainty with the variability across the different sites considered.
\end{abstract}

\section{INTRODUCTION}

The BioMoSA project was aimed at the improvement of the scientific basis for the application of biosphere models in the framework of long-term safety studies of radioactive waste disposal facilities [1]. The results will hopefully increase the transparency of biosphere modelling in long-term safety studies, improve the understanding of uncertainties, and enhance public confidence in the assessment of potential radiological dose to population groups far into the future. The project also aimed to provide implementers and regulator bodies with guidelines for performance assessments of repository systems. BioMoSA complements the work of the EU BIOCLIM project [2], which has been looking at the possible long term impacts on the safety of radioactive waste repositories in deep formations due to climate and environmental change.

The detailed objectives of the BioMoSA project were:

- To develop and test practical biosphere models for application in long-term safety studies of radioactive waste disposal at different European locations.

- To identify common and site-specific features, events and processes (FEP's) that need to be modelled.

- To identify principal fundamental differences between different sites. 
- To develop a generic biosphere tool for application in long term safety studies.

- To provide guidance in the application of the generic biosphere tool to proposed sites.

- To compare results from site-specific models to those produced with a generic model.

- To identify the possibilities and limitations for applying the generic biosphere tool in different national contexts.

- To provide guidance on how detailed specific sites have to be modelled in order to achieve credible and sufficiently reliable results in long-term performance assessment studies.

Calculations were performed for five selected sites in Europe using models developed by each BioMoSA partner. Deterministic runs were carried out to calculate annual individual doses to the critical groups and to rank the important exposure pathways. Doses were normalised with the activity concentration in water so that a direct comparison of the doses for each site could be made. A comparison of the uncertainty in the model results for the different sites was estimated by stochastic calculations. The most important parameters were identified for all sites and the sensitivity of the doses to variation of those parameters was estimated. The results were compared with the results of a generic biosphere model, which was used as a benchmark.

\section{SITE DESCRIPTION AND MODEL SETUP}

\subsection{Site description}

The five chosen European sites are classified in Table 1. These were characterised in terms of land use, freshwater use, natural resources, demography, topography, hydrology and hydrogeology, farming practices and animal husbandry, biota and human community. The geo-biosphere interfaces were also defined. The climate was characterised in terms of annual course of temperature, precipitation, humidity and evapotranspiration. The details of each site led to the construction of interaction matrices between media and processes from which the conceptual models were derived. The sites cover a wide range of environmental and agricultural conditions within Europe, hence the results from the study have a general validity for other European sites.

Table 1. Description of the sites considered in the study.

\begin{tabular}{|c|c|c|c|c|c|c|}
\hline Site location & $\begin{array}{l}\text { Climate } \\
\text { (Köppen } \\
\text { classification) }\end{array}$ & Land use & \multicolumn{4}{|c|}{ Release position } \\
\hline $\begin{array}{l}\text { Mol-Dessel, } \\
\text { Belgium }\end{array}$ & Humid subtropical & Pasture, farmland, fishing & Well & River & & \\
\hline $\begin{array}{l}\text { Gorleben, } \\
\text { Germany }\end{array}$ & Humid subtropical & Forest, pasture, farmland & Well & Pond & & \\
\hline 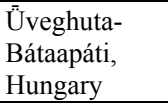 & Humid subtropical & Forest, farmland & Well & Lake & & \\
\hline Central Spain & Mediterranean & Forest, pasture, farmland & Well & Lake & River & \\
\hline $\begin{array}{l}\text { Fosmark } \\
\text { Region, } \\
\text { Sweden }\end{array}$ & Humid continental & Forest, wetlands, fishing & Well & Lake & $\begin{array}{l}\text { Agricultural } \\
\text { land }\end{array}$ & Coast water \\
\hline
\end{tabular}

\subsection{Radionuclides}

Nine long half-life radionuclides typically found in radioactive waste from nuclear power stations were selected, they were ${ }^{36} \mathrm{Cl},{ }^{79} \mathrm{Se},{ }^{99} \mathrm{Tc},{ }^{129} \mathrm{I},{ }^{135} \mathrm{Cs},{ }^{226} \mathrm{Ra},{ }^{231} \mathrm{~Pa},{ }^{230} \mathrm{Th},{ }^{237} \mathrm{~Np},{ }^{239} \mathrm{Pu}$ and ${ }^{238} \mathrm{U}$, along with the decay chains for ${ }^{226} \mathrm{Ra},{ }^{231} \mathrm{~Pa},{ }^{237} \mathrm{~Np},{ }^{239} \mathrm{Pu}$ and ${ }^{238} \mathrm{U}$. For short-lived daughters, secular equilibrium was assumed to be achieved instantly, therefore dose coefficients for a parent nuclide comprised of those of their short-lived daughters. 
The nuclides cover a wide range of environmental behaviour. Among the nuclides, $\mathrm{Cl}, \mathrm{Se}, \mathrm{Tc}$, and I are relatively environmentally mobile, whilst $\mathrm{Ra}, \mathrm{Pa}, \mathrm{U}, \mathrm{Np}$ and $\mathrm{Pu}$ are relatively immobile.

\subsection{Generic model}

Within BioMoSA both site-specific and generic biosphere models were derived using the Reference Biosphere Methodology that was developed within the international BIOMASS project [3]. This is a staged approach in which each stage introduces further detail so that a coherent biosphere description and corresponding conceptual, mathematical and numerical models can be constructed.

The development of the generic biosphere also took into account the functionality of the NRPB BIOS code [4] and the transfer processes used in BIOS. The generic biosphere model was used to represent a typical repository site within the European Union with related environmental and societal conditions. The principal elements in the biosphere include climate, geological conditions, hydrology and hydrogeology, biota and their interactions in this biosphere. Human activities were also included in order to identify the important exposure pathways and groups. In order to be a generic tool, the generic biosphere took account of all the features (e.g. climate conditions) and pathways identified as being important in the five specific sites considered in this study.

The resulting generic biosphere model BIOGEM is shown in Figure 1. It was designed so that particular transport processes and pathways can be switched on and off. If the model, for example, was applied to an inland site, then the marine pathways would not be taken into account.

For each of the sites a corresponding biosphere model was developed specifically from the generic biosphere model. For each of the sites, as far as possible, site-specific parameters were selected for element-independent parameters (e.g. irrigation rates, agricultural practices, human consumption rates, potential critical groups) and element-dependent parameters (e.g. transfer factors soil-plant, distribution coefficients, migration of radionuclides in soil). For other model parameters for which no site data was available, NRPB data was used. The model complexity was consistent with the available data for the model parameters. Also, simpler models facilitate an uncertainty analysis as results are generally more transparent and easier to interpret.

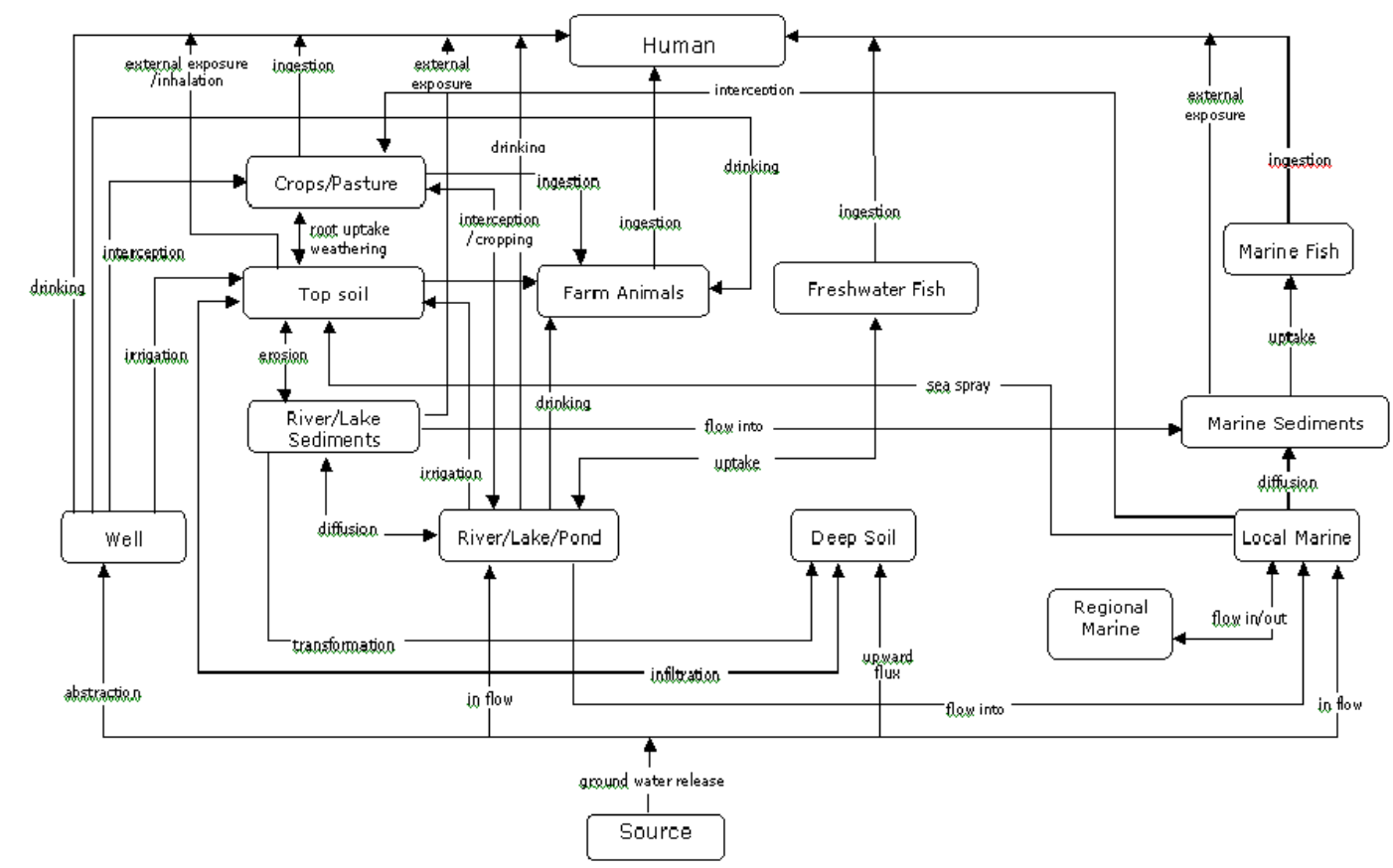

Figure 1. Conceptual model for BIOGEM. 


\section{RESULTS}

For calculation purposes and to make the comparisons between sites and between the site-specific and the generic model easier, the doses were normalised with the radionuclide concentrations in the drinking water for humans $\left(1 \mathrm{~Bq} / \mathrm{m}^{3}\right)$. Hence, the dose results were given as $\mathrm{Sv} /$ a per $\mathrm{Bq} / \mathrm{m}^{3}$.

The calculations were made for present day conditions at each of the sites. For each site deterministic results were calculated and the uncertainties of the results estimated.

Table 2 shows the percentage contribution of the exposure pathways to the total doses for adults for the well scenario for ${ }^{135} \mathrm{Cs}$ for the site specific and BIOGEM models. The site specific results compared favourably with the BIOGEM results for most pathways, though there were some differences, for example, in the pork pathway for Hungary. The exact contribution of pathways varied with nuclide but in all cases, ingestion was the dominating exposure route with one of the most important ingestion pathways being the consumption of drinking water. Other potential important pathways were the ingestion of cereals, root crops, fruit vegetables, beef, milk, pork and fruit. There was no general pattern, the varying importance of the foods depended on how the pathway had been modelled and the values of the parameters that had been selected for each site. An example of this was the variation in intake rates, which often reflected national consumption habits. The Spanish model, for instance, explicitly took into account the consumption of citric fruit, whereas fresh water fish figure highly in the Swedish diet. External exposure was only relevant for ${ }^{226} \mathrm{Ra}$ and ${ }^{238} \mathrm{U}$.

Figure 2 a) shows the ratio of BIOGEM to site specific adult total doses for the well scenario for all nuclides across all sites. It is seen that the difference in results was in general less than a factor of 10 . Any difference in the total doses was usually due to the difference in the dose for a particular pathway. Figure $2 \mathrm{~b}$ ) shows a similar pattern for the ratio of BIOGEM to site specific infant total doses for the lake scenario across all sites (Belgium does not have a lake scenario). Here, the biggest disparity between BIOGEM and site specific models was in German total doses for ${ }^{135} \mathrm{Cs}$. In the both models for the lake, doses were due to fish consumption only. It is believed that the differences arose because the German model used sediment concentration to calculate fish doses, whereas BIOGEM used the water concentration.

Figure 3 a) shows a direct comparison of the stochastic results for infant total doses for the river scenario obtained using the Belgian site specific model and BIOGEM. It shows that the $5^{\text {th }}$ and $95^{\text {th }}$ percentiles of the uncertainty distributions of doses to adults obtained by the two models overlapped for all nuclides except for ${ }^{79} \mathrm{Se}$. This was due to the interpretation of some of the parameter values for selenium, which has a complex chemistry in soil. By contrast the stochastic results infant total doses for the rising ground water scenario are presented in Figure $3 \mathrm{~b}$ ). There was no overlap of the Swedish $5^{\text {th }}$ and $95^{\text {th }}$ percentile doses and BIOGEM doses, with the BIOGEM doses being several orders of magnitude greater than the Swedish results. This is because the Swedish model has a relatively detailed representation of groundwater, whereas in BioGeM it is simply modelled as a direct release to the deep soil compartment. The experimental database to model the exchange from the deep soil to the upper soil is poor which causes uncertainties in modelling. This is particularly important if the deep soil is considered as the geosphere-biosphere-interface.

Table 2. Contribution of exposure pathways for adult well doses for ${ }^{135} \mathrm{Cs}$.

\begin{tabular}{|l|c|c|c|c|c|c|c|c|c|c|}
\hline \multirow{2}{*}{ Pathway } & \multicolumn{9}{|c|}{ Site specific } & \multicolumn{4}{c|}{ BIOGEM } \\
\cline { 2 - 12 } & $\mathrm{B}$ & $\mathrm{G}$ & $\mathrm{H}$ & $\mathrm{E}$ & $\mathrm{S}$ & $\mathrm{B}$ & $\mathrm{G}$ & $\mathrm{H}$ & $\mathrm{E}$ & $\mathrm{S}$ \\
\hline Drinking water & 36.5 & 46.7 & 1.5 & 1.5 & 25.0 & 52.0 & 43.0 & 14.0 & 3.0 & 19.0 \\
\hline Leafy vegetables & 7.1 & 2.0 & 2.8 & 5.7 & 27.1 & 5.0 & 2.0 & 3.0 & 10.0 & 26.0 \\
\hline Cereals & 0.0 & 9.7 & 3.9 & 2.8 & 0.0 & 0.0 & 8.0 & 0.0 & 12.0 & 0.0 \\
\hline Root crops & 33.2 & 7.8 & 21.1 & 5.8 & 35.4 & 16.0 & 9.0 & 21.0 & 14.0 & 43.0 \\
\hline Fruit & 1.8 & 7.0 & 38.0 & 23.4 & 0.0 & 3.0 & 11.0 & 42.0 & 31.0 & 0.0 \\
\hline Milk & 9.5 & 16.7 & 6.5 & 4.9 & 2.9 & 9.0 & 4.0 & 3.0 & 5.0 & 2.0 \\
\hline Beef & 11.9 & 2.4 & 1.2 & 1.5 & 6.0 & 14.0 & 4.0 & 0.0 & 3.0 & 10.0 \\
\hline Pork & 0.0 & 5.7 & 19.7 & 43.1 & 0.0 & 0.0 & 18.0 & 2.0 & 19.0 & 0.0 \\
\hline Chicken & 0.0 & 0.0 & 3.5 & 4.3 & 0.0 & 0.0 & 0.0 & 13.0 & 3.0 & 0.0 \\
\hline Others & 0.0 & 2.0 & 2.0 & 7.0 & 3.6 & 1.0 & 1.0 & 2.0 & 0.0 & 0.0 \\
\hline B: Belgium G: German H: Hungary E: Spain S: Sweden & & & & & \\
\hline
\end{tabular}




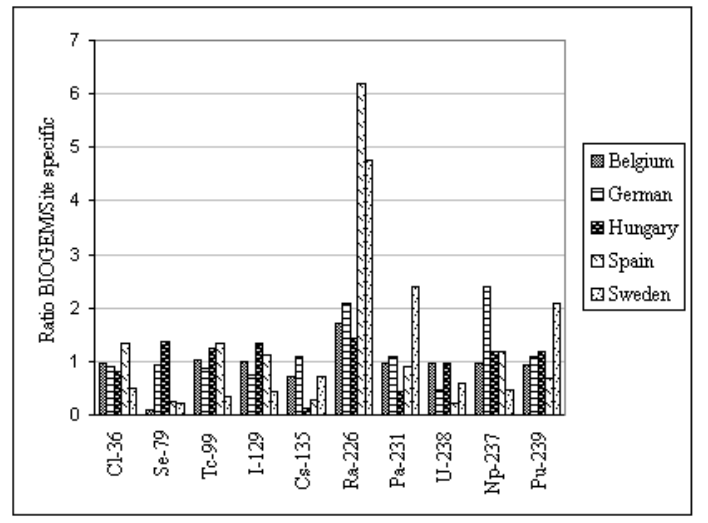

a)

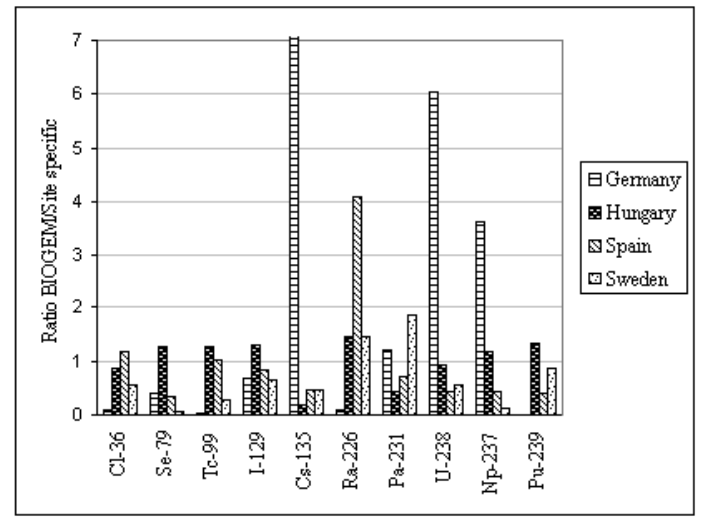

b)

Figure 2. Comparison of BIOGEM and site specific for a) adult total doses for the well scenario, b) infant total doses for the lake scenario.

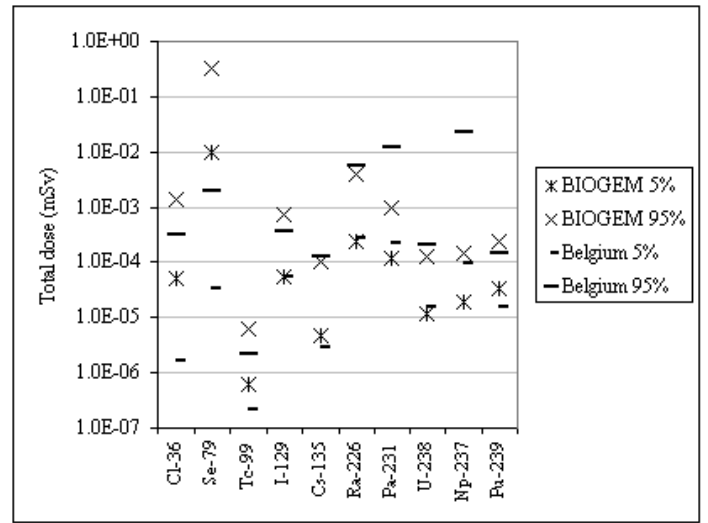

a)

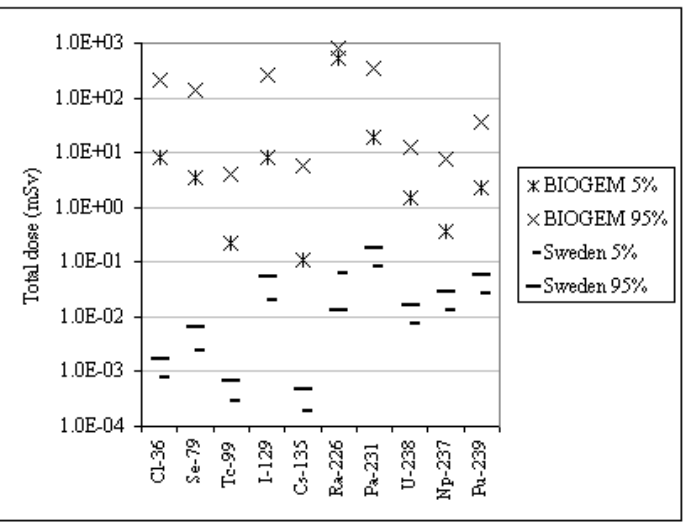

b)

Figure 3. Comparison of stochastic results for BIOGEM and site specific for a) infant total doses for the Belgium river scenario, b) infant total doses for the Swedish rising groundwater scenario.

\section{CONCLUSIONS}

The model development in the BioMoSA study was carried out for five European sites that cover a wide range of agricultural, climatic and social conditions. In parallel, a generic model was developed that was able to simulate all features, events and processes that were considered in the site-specific models. The model results from site-specific models were compared for both deterministic and stochastic calculations. The site-specific model results were compared with those obtained using the generic model.

The BIOMASS Reference Biosphere Methodology proved to be useful for setting up a biosphere model. The FEP list was a good guide for identification of pathways and processes, however it does not replace the experience of the modeller. The model approaches were still subject to individual interpretation of the processes and the available parameters.

In general, there was an acceptable agreement between the results obtained with the generic and the site-specific models. The interpretation of data, especially when the data was poor, was a major source of uncertainty. This was especially true for ${ }^{36} \mathrm{Cl},{ }^{129} \mathrm{I}$ and ${ }^{79} \mathrm{Se}$. The speciation and the 
interaction of these elements with soil constituents is an area that is poorly understood. Although the models considered the same processes, different approaches were applied in some cases, and this again led to differences in some results.

The sites considered covered a wide range of environmental and climatic conditions. Although the influence of the climate was not a major objective of the BioMoSA project, the comparison of the results for the five sites indicate that the impact of climatic factors is relatively low.

\section{References}

[1] G. Proehl, Q. Chen, P. Pinedo, G. Olyslaegers, I. Simón, U. Bergstrom, B. Hallberg, B. Kanyar, R. Kowe, S.F. Mobbs and Th. Zeevaert, Biosphere Models for Safety Assessment of radioactive waste disposal based on the application of the Reference Biosphere Methodology, BioMoSA final report, (2004).

[2] D. Texier, P. Degnan, M.F. Loutre, D. Paillard and M. Thorne, Modelling BIOsphere systems under CLIMate change for radioactive waste disposal, Proceedings of the International High-Level Waste Management Conference, Las Vegas, USA, (2003).

[3] Reference Biospheres for Solid Radioactive Waste Disposal: Volume I - OVERVIEW v3.0, BIOMASS Theme 1, Draft TECDOC, (2001), International Atomic Energy Agency, Vienna.

[4] J.S. Martin, I.M. Barraclough, S.F. Mobbs, R.A. Klos and G. Lawson, User guide for BIOS_3A (1991), NRPB-M285. 